\title{
AS HOMOSSEXUALIDADES E A PSICOLOGIA: UM ESTUDO SOBRE O DESEJO HOMOERÓTICO AMPARADO NA RESOLUÇÃO 001/99 DO CONSELHO FEDERAL DE PSICOLOGIA
}

\author{
Yvisson Gomes dos Santos ${ }^{1}$
}

\section{RESUMO}

O presente artigo pretende discutira Resolução CFP 001/99 do Conselho Federal de Psicologia que "Estabelece normas de atuação para os psicólogos em relação à questão da Orientação Sexual", objetivando analisar a despatologização das homossexualidades no referido documento. A ideia de perversão, parafilia e doença foram retiradas deste documento em que o psicólogo se utiliza para balizar suas relações terapêuticas com seu paciente homossexual. Questões como promoção da afirmação da patologia gay, divulgação e propagação dessas ideias dentre outras, foram todas vetadas aos profissionais da psicologia em sua práxis. Para tal expediente,aplicou-se os referencias teóricos de estudos sobre a homossexualidade dentro dos documentos e cartilhas oficiais do Conselho Federal de Psicologia (Cf. CFP, 1999; 2005), do Conselho Regional de Psicologia de São Paulo (Cf. KAHHALE, 2011; UZIEL, 2011), bem como do Conselho Regional de Psicologia de Alagoas (Cf. GOMES, 2010). Utilizou-se dos conceitos foucaultianos dos dispositivos da sexualidade (Cf. FOUCAULT, 1979; 1988; 2009) para se entender o homoerotismo tanto na história da sexualidade do sujeito, bem como na articulação dessa história com a Resolução 001/99 como instrumento legislativo endereçado aos psicólogos. Frisou-se neste artigo a historizicação das homossexualidades, levando em consideração os momentos de anacronismos sobre tal comportamento sexual, bem como os momentos de permissão e/ou tolerância dentro da sociedade ocidental e oriental. A Resolução 001/99 coloca aos psicólogos a perspectiva de não incitar a cura gay, pois não se trata mais de doença de acordo com a Organização Mundial de Saúde (OMS), e também pelos códigos psiquiátricos da contemporaneidade, a saber, o CID-10 e o DSM-4. Concluímos que houve um considerável avanço nessa área "psi" aos pacientes que chegam ao consultório terapêutico com intuito de se compreenderem sujeitos de sua história pessoal, onde o lugar do psicólogo é de abarcar as polissemias do psiquismo humano e vetar quaisquer atitudes que venham a coibir essas polissemias no sentido de corroborar com a patologização homossexual, sabendo, mesmo assim, que com estas resoluções, nada impede de haver manifestação de preconceito contra os homossexuais (homofobia), isso deve sempre estar claro aos psicólogos como um alerta de que a mudança de pensamento se dará de dentro para fora, requerendo de nós, psicólogos, e da sociedade como um todo, um ajuste de comportamento pautado na dignidade e no conhecimento da diversidade sexual através de uma autoanálise e de uma visão ideológica plurirreferenciada com finalidade a uma prática profissional mais consciente.

Palavras-chave: Homoerotismo. Psicologia. Despatologização.

\footnotetext{
${ }^{1}$ Psicólogo, filósofo, especialista em Linguística pela UNICID/AAL e mestrando em Educação Brasileira pela UFAL. E-mail: yvissongomes@hotmail.com.
} 


\section{ABSTRACT}

This article discusses the CFP Resolution 001/99 of the Federal Council of Psychology that "establishes standards of performance for psychologists on the issue of sexual orientation", aimed at analyzing the depathologization of homosexualities in this document. The idea of perversion, paraphilia and disease were withdrawn from the document in which the psychologist is used to mark their therapeutic relationships with their homosexual patients. Issues such as promoting the affirmation of gay disease, dissemination and propagation of these ideas among others, have all been vetted professionals of psychology in their practice. For this record, we applied the theoretical references of studies on homosexuality within the official documents and brochures of the Federal Council of Psychology (Cf. CFP.1999; 2005) , the Regional Board of Psychology of St. Paul (Cf. KAHHALE 2011; UZIEL 2011 ) and the Regional Council of Psychology of Alagoas (Cf. GOMES , 2010). We used the Foucauldian concepts of the devices of sexuality (Cf. FOUCAULT, 1979; 1988; 2009) to understand both the homoeroticism in the history of sexuality of the subject as well as the articulation of this story with Resolution 001 / 99 as addressed legislative instrument psychologists. He stated that this article historizicação of homosexualities, taking into account the moments of anachronisms about such sexual behavior as well as the moments of permission and / or tolerance within the western and eastern society. Resolution 001/99 puts to psychologists the prospect of not inciting gay cure, because it is not over according to the World Health Organization (OMS) disease, and also by the contemporary psychiatric codes, namely CID-10 and DSM-4. We conclude that there has been considerable progress in this area, "psi" to patients who arrive at the office with therapeutic intent to understand subjects of his personal history, the place where the psychologist is to embrace the polysemy of the human psyche and veto any action that may inhibit these polysemies towards corroborate the pathologizing homosexual, knowing even then that with these resolutions, there is nothing to prevent the manifestation of prejudice against homosexuals (homophobia), it should always be clear to psychologists as a warning that changing thought will occur from the inside out, requiring of us, psychologists, and society as a whole, an adjustment of behavior grounded in dignity and knowledge of sexual diversity through a self-analysis and a plurirreferenciada ideological vision with purpose to professional practice more aware.

Keywords: Homoeroticism. Psychology. Depathologization. 


\section{Introdução}

Falar sobre sexualidade no espaço reservado ao divã ou a uma sala com duas poltronas confortáveis uma em frente à outra é fato corriqueiro nas relações terapêuticas entre psicólogo e paciente. E o tema do homoerotismo é algo presente nestas relações ${ }^{2}$.

Quando se fala sobre a psicologia e o homoerotismo ${ }^{3}$ o tecido conceitual e vivencial da dupla em questão pode ser assim sintetizada, a saber: daquele que exprime seu desejo ao terapeuta no recôndito do consultório, despertando-se ao desejo que lhe é inerente (homoerótico), havendo dessa sorte uma proposta encaminhada ao paciente para uma contradança com seu terapeuta, onde este se coloca na ordem da escuta e da compreensão do que lhe é dito, verbalizado e sentido pelo seu interlocutor, servindo-se como uma tela em branco no sentido lockeano - de uma tábula rasa -, aos enunciados de seu cliente para maior apreensão de seus afetos e de seus processos ideativos. Este cliente se sente a vontade para se expressar e se compreender enquanto sujeito de desejo.

A psicologia vem caminhando em direção a uma postura atualizada sobre atitudes éticas e não discriminatórias, e o tema do homoerotismo ou das homossexualidades é uma dessas atitudes. Para ratificar, o Conselho Federal de Psicologia comemora a mais de uma década a Resolução 001/99 na qual retira as homossexualidades do âmbito da patologização, das parafilias e das perversões, antes endereçadas aos homossexuais.

\footnotetext{
${ }^{2}$ Os instrumentos físicos em um consultório terapêutico são diversos. Neste artigo tanto o divã (psicanálise) quanto as poltronas (as terapias humanistas dentre várias) não representaram uma disparidade para o assunto em questão: o homoerotismo. Da mesma forma nesse texto expressões como pacientes, clientes e analisandos se equivalem. A ideia é de que essa Resolução CFP 001/99 abrangeu a todos os "psi", independente das epistemologias da psicologia no tocante as metodologias de tratamento desses profissionais. O lugar se tornou o mesmo com relação às homossexualidades e a sua despatologização, graças à referida Resolução (KAHHALA, 2001).

${ }^{3}$ As terminologias homoerotismo e homossexualidades são usadas neste texto de acordo com os referenciais teóricos e legislativos que o embasam. Consideramos que existem as homoafetividades, mas entendemos que nem todas as relações homossexuais são homoafetivas, pois pode haver relações sexuais homossexuais em que o componente afetivo seja descartável, como as relações entre garotos de programa gays e seus clientes gays, dentre outros (FRY, 1982).
} 
Tal resolução serve de anteparo ético e de ferramenta para o psicólogo no trato profissional com os seus pacientes homossexuais em consultório, fazendo-o em sua práxis um leitor consciente da diversidade gay, e salvaguardando no lidar de sua postura profissional a não propagação da homofobia e a evitação de cura, já que não se está falando mais de doença. É de nota que a metáfora dos conceitos da psicanálise deverá, em alguns momentos deste artigo, fazer-se presentificada, mas que pontuamos que em outros âmbitos da atuação "psi", tais como em escolas, no trabalho, na saúde pública, dentre outros, a presente Resolução 001/99 deve ser aplicada e fomentada nessas instâncias, além da clínica.

Com esta resolução de eticidade do CFP pôde-se fazer, por meio deste artigo, uma intersecção com a leitura do desejo homoerótico visto sob a perspectiva foucaultiana, principalmente pelo vértice dos dispositivos da sexualidade estudados pelo filósofo. Objetivou-se identificar alguns fatores que traçaram a aversão aos homossexuais na história da sexualidade do sujeito para entender o porquê desta resolução do CFP ser urgente e necessária aos nossos dias.

\section{Resolução CFP 001/99 como norteador para uma nova práxis profissional do psicólogo ou: o que já se alcançou por meio desta resolução?}

As normatizações que são características das sociedades civilizadas são instrumentos que tendem a ordenar o comportamento do homem em sociedade.Esse tipo de ordenamento fez os indivíduos submetidos a leis, que de um certo modo, trouxeram tranquilidade jurídica, social, cultural e política aos cidadãos. Por outro lado, criaram-se as penalidades aos crimes para aqueles que não se encaixavam nas diretrizes impostas pela civilização, acarretando em castigos de toda a sorte aos insubordinados à ordem estabelecida. $\mathrm{O}$ crime era penalizado, e na metáfora dessa penalização o governo (soberano, lei, estatutos) triunfava. Segundo Foucault:

Sendo princípio de comunicação do crime com a pena, ela é por outro lado a exasperação do castigo em relação ao crime. Realiza ao mesmo tempo a ostentação da verdade e do poder; é o ritual do inquérito que termina e da cerimônia onde triunfa o soberano (FOUCAULT, 2009, p 55). 
Foi assim nas sociedades antigas como a mosaica e os dez mandamentos, bem como a mesopotâmica do código de Hamurabi"olho por olho e dente por dente" - , que de certa maneira,escreveram os códices de boa convivência entre os homens e as suas penalidades e castigos aos que não obedecessem as regras vigentes. Em um grau elevado do estoicismo romano temos: "Dura Lex Sed Lex" (a lei é dura, mas é a lei).

A psicologia dentro da perspectiva normatizadora da práxis profissional, mas de forma contemporânea e assumindo a humanização dos sujeitos que vêm aos consultórios para tratamento psicoterápico, propôs a Resolução CRP 001/99 que "Estabelece normas de atuação para os psicólogos em relação à questão da Orientação Sexual”. Um passo legislativo que foi ratificado pela exclusão do homossexualismo (ismo) dos Códigos Internacionais de Doenças (CID-10 e DSM-4) e, principalmente, da Organização Mundial de Saúde (OMS), desde 17 de maio de 1992.

$\mathrm{O}$ que reza essa Resolução CFP $001 / 99$ com relação às homossexualidades e ao profissional da psicologia?

Preferimos cotejá-la com o intuído de deixar registrada a importância deste documento oficial para os psicólogos e demais interessados na área das humanidades e da saúde. O texto inicia-se assim: "Considerando que na prática profissional, independentemente da área em que esteja atuando, o psicólogo é frequentemente interpelado por questões ligadas à sexualidade" (RESOLUÇÃOCFP No 001/99, p.1)

Precisamos dizer que essa interpelação é constante, poderíamos dizer para ilustrar, e como contribuição a ciência psicológica, que a via mestra de uma psicoterapia seja a sexualidade, isso já nos falava Freud nos Estudos Sobre a Histeria (FREUD, [1893]1996), estabelecendo um diálogo contínuo entre o desejo do paciente e o desejo do analista, tendo como mola propulsora a transferência. Devemos pontuar que cabe ao psicólogo estar preparado para lidar com seus desejos inconscientes, e principalmente, o do seu analisando.

Continuemos: "Considerando que a forma como cada um vive sua sexualidade faz parte da identidade do sujeito, a qual deve ser compreendida na sua totalidade" (ibidem, p. 2). 
Nesse parágrafo, vê-se nitidamente que a identidade do sujeito deve ser compreendida de forma total. A ideia dessa totalidade está nos aspectos biopsicossociais e espirituais do paciente (BOCK et alii, 2001). O psicólogo deve entendê-lo por esse vértice, independente de correntes psicológicas, e não reduzir o sujeito a fragmentos psíquicos ou delimitá-lo por um único vértice, podendo recorrer em prejuízos ao bem-estar psíquico do mesmo.

Continuamos com os considerandos da referida resolução, lê-se:

Considerando que a homossexualidade não constitui doença nem distúrbio e nem perversão;

Considerando que há, na sociedade, uma inquietação em torno de práticas sexuais desviantes da norma estabelecida sócioculturalmente;

Considerando que a Psicologia pode e deve contribuir com seu conhecimento para o esclarecimento sobre as questões da sexualidade, permitindo a superação de preconceitos e discriminações. Resolve [...] (Ibidem, p 2)

Devemos pontuar as considerações dessa resolução. A primeira que nos chama atenção é a de que a "homossexualidade não constitui doença nem distúrbio e nem perversão".

Neste momento fica claro que qualquer forma de definir patologização à homossexualidade recorre em erro crasso e passível de punição ao psicólogo que a considere patologia.É uma forma de exigir que os direitos humanos sejam respeitados e que as diversas correntes da psicologia devam com esses considerandos entender a verticalidade e a perspectiva dinâmica do assunto em questão, pois ela é "independentemente da linha teórica dentro da Psicologia. Ou seja, é um aspecto do humano que, independentemente do peso teórico assumido, sempre exigirá respostas dos profissionais psicólogos" (KAHHALE, 2001, p. 22).

Possivelmente, os binarismos existentes nas relações terapêuticas com inclusão à diversidade sexual não devem ser vistos como:“crenças em uma verdade imutável, universal, e, portanto, a-histórica e neutra; numa apreensão objetiva do mundo e do ser humano"(COIMBRA \& NASCIMENTO [2001] apud UZIEL, 2011, p. 20). Mas como "o desenvolvimento de um direito da sexualidade" (RAUPP, 2006, p. 78), em exprimir-se livremente sem coerção dentro do orbe "psi". 
Cabe ao psicólogo compreender os aspectos culturais dos homoeróticos em seu território terapêutico, mas também de apreender a complexidade que a diversidade sexual anuncia através das homossexualidades dos seus clientes, sempre na sua práxis profissional consciente.

Chegaremos agora nos artigos que perfazem a Resolução CFP $\mathrm{N}^{\circ} 001 / 99$. Vamos a eles:

"Art. $1^{\circ}$ - Os psicólogos atuarão segundo os princípios éticos da profissão, notadamente aqueles que disciplinam a não discriminação e a promoção e bem-estar das pessoas e da humanidade" (Ibidem). Este artigo está em consonância com o Código de Ética Profissional do Psicólogo quando se lê: "O psicólogo trabalhará visando promover a saúde e a qualidade de vida das pessoas e das coletividades e contribuirá para a eliminação de quaisquer formas de negligência, discriminação, exploração, violência, crueldade e opressão" (2005, p. $5)$.

Com os artigos posteriores lemos:

Art. $2^{\circ}-$ Os psicólogos deverão contribuir, com seu conhecimento, para uma reflexão sobre o preconceito e o desaparecimento de discriminações e estigmatizações contra aqueles que apresentam comportamentos ou práticas homoeróticas.

Art. $3^{\circ}$ - Os psicólogos não exercerão qualquer ação que favoreça a patologização de comportamentos ou práticas homoeróticas, nem adotarão ação coercitiva tendente a orientar homossexuais para tratamentos não solicitados.

Parágrafo único - Os psicólogos não colaborarão com eventos e serviços que proponham tratamento e cura da homossexualidade.

Art. $4^{\circ}-$ Os psicólogos não se pronunciarão, nem participarão de pronunciamentos públicos, nos meios de comunicação de massa, de modo a reforçar os preconceitos sociais existentes em relação aos homossexuais como portadores de qualquer desordem psíquica.

Encontramos no Artigo $2^{\circ}$ palavras-chave que se é necessário evitar: preconceito, discriminação e estigmatizações. De acordo com Kahhale “esta explicitação era necessária, porque a partir daí tínhamos uma forma de começar a nortear a formação e a atuação dos profissionais psicólogos" (2001, p.22). 
Na interpretação dos artigos subsequentes o $3^{\circ}$ e o $4^{\circ}$, Edna Kahhale compreende que esses artigos:

significam que é proibido fazer terapia para mudar a orientação/opção da sexualidade da pessoa, sem que isso seja diretamente acordado. O psicólogo não colaborará com eventos e serviços que proponham tratamento e cura das homossexualidades.

Nós, da área da Psicologia, somos a única categoria profissional que coloca isso claramente. Os psicólogos não se pronunciarão nem participarão de pronunciamentos públicos nos meios de comunicação de massa de um modo a reforçar os preconceitos sociais existentes em relação aos homossexuais, como portadores de qualquer desordem psíquica (ibidem, p. 22)

Nas linhas que se subscrevem os referidos artigos encontramos explicitamente o respaldo contra a homofobia, no qual os homossexuais na história eram vistos como os de "pecado nefando, o terceiro sexo" dentre outras denominações. A busca da psicologia com o referido decreto é de fomentar a não discriminação contra os homossexuais. Pois:

Cabe frisar que as resoluções contra a discriminalização da alteridade (gay), entendendo-a como concepção que parte do pressuposto básico de que todo o homem interage $\mathrm{e}$ interdepende de outros indivíduos, que ao mesmo tempo pode ser o igual, pois não podemos elidir algo que é inseparável ao nosso meio social, que essas resoluções mesmo assim, não impedem de haverem manifestações de preconceitos contra os homossexuais e afins (homofobia), e isso deve sempre estar claro aos psicólogos como um alerta de que a mudança de pensamento se dará de dentro para fora, requerendo de nós, e da sociedade como um todo, um ajuste de comportamento pautado na dignidade e no conhecimento da liberdade de expressão sexual através de uma auto-análise e de uma visão ideológica plurirreferenciada com finalidade a uma prática profissional mais consciente (GOMES, 2010, p. 3).

As práticas terapêuticas devem estar respaldadas na dignidade do ser humano, com sua liberdade de expressão, em que a localização do homoerotismo em nossa sociedade contemporânea deverá estar direcionada a uma práxis profissional consciente do psicólogo. Este, entendendo seus instrumentos teóricos e colocando-os em prática, deve observar que o estranho ou o alter/alteridade somos todos nós, dependendo do olhar que se tem, ou do ponto de vista dos sujeitos.

Ao profissional de psicologia esse olhar precisa ser "da representação desejante do outro" (LACAN, 1998) que se mostra na sala de terapia, 
não numa relação dual circunscrita sob as ordens do preconceito, mas um caleidoscópio sobre as possiblidades e desejos que advêm do gay.

\section{A psicologia e o desejo homoerótico ou o olhar para as constelações}

A Psicologia é balizada por várias teorias do conhecimento que trafegam pela sua história científica. Pelo viés psicanalítico, ela entende que a sexualidade humana é inerente ao sujeito não somente quando a utiliza para fins de procriação, mas, principalmente, para sua identidade de prazer e satisfação interdita pela via primordial do desejo, pois: "o desejo é um movimento psíquico de origem interna que visa obter uma satisfação interdita ou reencontrar um gozo primordial cujos vestígios se fixaram no inconsciente" (MOJILLA, 2005, p.459).

De acordo com Marilena Chauí a etimologia da palavra desejo:

Deriva-se do verbo desidero que, por sua vez, deriva-se do substantivo sidus (mais usado como no plural como sidera), significando a figura formada por um conjunto de estrelas, isto é, as constelações. Porque se diz dos astros, sidera é empregado como palavra de louvor - o alto - e, na teologia astral ou astrologia, é usado para indicar a influência dos astros sobre o destino humano (1990, p. 22).

Temos uma palavra que escandida pelo grego faz-se olhar a sidera, ao espaço sideral, uma forma de falar do desejo em sua etimologia. A partir dessa definição da palavra em questão, encontramos outra definição mais aproximada ao que se tenta investigar. Recorremos, mais uma vez, ao conceito da psicanálise para falar sobre este desejo. Vamos à definição:

O desejo nasce do afastamento entre a necessidade e a exigência; é irredutível à necessidade, porque não é fundamentalmente relação com o objeto real, independente do indivíduo, mas com o fantasma (fantasia); é irredutível à exigência na medida em que procurar impor-se sem ter em conta a linguagem nem o inconsciente do outro, e exige ser reconhecido em absoluto por ele (LAPLANCHE \& PONTALIS, 1970, p. 116).

O desejo exige ser reconhecido, ou seja, aquele que deseja precisa ser redescoberto pelo outro numa relação dialética. Temos duas definições de desejo (uma da ordem cosmológica 
e etimológica) e outra pela via da psicanálise (o outro que identifica meu desejo nas trocas simbólicas desse mesmo desejo). Ambas constroem o psicodinamismo do sujeito através do intermezzo da falta, pois "o desejo chama-se [...], carência, vazio que tende para fora de si em busca de preenchimento, aquilo que os gregos chamam de hormê" (CHAUí, 1990, p. 23). A falta é o que caracteriza a subjetividade do ser de desejo, a saber, de todos nós, em qualquer instância será assim, de acordo com os pressupostos da psicologia profunda.

Nas tentativas de definição do desejo, nos deparamos com a dialética do desejo homoerótico que em linhas gerais nada mais é que o desejo sexual endereçado a iguais (homos). Quer seja um desejo homossexual masculino ou feminino, ambos têm suas vias de satisfação que se concretiza no fantasma ou na fantasia, pela ordem inconsciente, e se efetiva no aspecto físico através coito em si.

Deve-se dizer que nem sempre o desejo gay foi aceito na sociedade ocidental. Sabemos das interdições bíblicas, de destruição de cidades que professavam o desejo pagão como Sodoma e Gomorra (GÊNESIS, 1994), devido a práticas "sexuais ilícitas" ou, indo um pouco além, a eliminação "do amor que não ouça dizer seu nome", segundo o irlandês Oscar Wilde (1998, p. 73), caminhando aos campos nazistas, colocando os "anormais" no epicentro da intolerância. Neste, foram os aspectos da proscrição que incomodavam e que eram ameaçadores, pois delapidavam com a ideologia de "pureza racial" vigente na época. A construção da dignidade homoerótica se refez ao se mostrar que qualquer forma coercitiva de poder era uma lembrança à submissão eugenista da ciência médica do século XIX, e desta sorte, homofóbica.

Já em outras sociedades como as orientais, o homoerotismo era natural, os deuses se compraziam com quaisquer objetos de desejo, sendo homens ou mulheres ou pares iguais. O Hinduísmo representa esse vertente da permissão ao amor gay dentro de seu panteão.

Na Grécia antiga ou clássica era natural a pederastia. Homens mais velhos que iniciavam os rapazes à filosofia do amor e a como se viver na pólis. No Banquete de Platão a ideia de promover uma elegia ao Amor (Eros) levou os confrades à festa de Agatão com intuito de proclamá-lo.

O tema do dia era sobre o amor ou um manifesto ao amor entre homens (erômenos e erastes). Segundo o dramaturgo Aristófanes, que se encontrava no Banquete, ele afirmava que em tempos cosmogônicos havia três seres circulares. Um macho e macho, outro macho e fêmea e outro fêmea e fêmea. Esses seres rebelaram-se contra Zeus e foram 
cortados ao meio, vivendo hoje cada um em busca de sua metade, tal como uma "téssera complementar". O que nos identifica através dessa cisão é o umbigo, marca deixada como lembrança mítica dessa separação (PLATÃO, 1991)

Talvez, Sócrates, utilizando-se da fala de Diotima de Mantineia tenha dado luz à origem do desejo ou do amor. Em sua interlocução com os convivas ele falava de dois deuses, uma faltosa e outro ardiloso que tiveram relação sexual na festa de Afrodite, nascendo o Amor que corresponde à astúcia (Poros) e a falta ou penúria (Pênia). Daí concluindo-se ser o desejo faltoso que se utiliza de artifícios para conquistar seu objeto de desejo intermitentemente (Ibidem, 1991). E nós não somos assim quando amamos a outrem, ou quando nos afastamos de nosso objeto de amor articulando de todas as formas o regresso ou o retorno do amado ou da amada?Artimanhas do desejo que é falta.

Ocorre-nos, agora, uma pergunta: sabemos que o desejo homoerótico é faltoso (de acordo com a teoria freudiana), tal como o de todo ser humano (dai deduzir que não haja cura para os gays), e de que o consentimento do mesmo passou por uma história longínqua de aceitação e de exclusão nas sociedades. Pois bem, como entender essa não aceitação na historia da sexualidade da humanidade? Quais os dispositivos que a sexualidade imprimiu na construção do homoerotismo? E o que a Resolução 001/99 tem haver com essa questão? Recorremos agora ao filósofo Michel Foucault.

\section{Foucault e os dispositivos da sexualidade e o Decreto CFP 001/99: algumas considerações}

Michael Foucault é um pensador estudado e conhecido. Há várias tentativas feitas para sistematizar e periodizar sua obra e pensamento. A maioria dos estudiosos e especialistas foucaultianos fala em três fases ou etapas caracterizadas: como a primeira fase arqueológica;

período das obras História da Loucura (1961) até Arqueologia do 
Saber (1969) passando por O nascimento da Clínica e As Palavras e as Coisas; a segunda fase genealógica com A Ordem de Discurso (1971) até o primeiro volume de História da Sexualidade- a vontade de saber, passando por Vigiar e Punir; e, por fim, a terceira fase ética que inclui os volumes 2 e 3 de História da Sexualidade- O Uso dos Prazeres e O cuidado de Si - publicado um mês antes de sua morte, em 1984 (VEIGA-NETO, 2007).

Elegemos a concepção de Foucault acerca da sexualidade para a compreensão e o entendimento do homoerotismo. Em primeira instância para Foucault esse termo é pertencente à modernidade, tal como a ideia de subjetividade. $\mathrm{O}$ termo homoerotismo é nascido no berço da sociedade vitoriana, enquanto nomenclatura e etiologia, e por isso tem circunscrita suas definições nesta mesma sociedade. Como, pergunta-se? Através dos dispositivos da sexualidade que conferem legitimidade e visibilidade ao termo homoerotismo. Desta feita, o que vem a ser os dispositivos da sexualidade para o nosso filósofo? Citamos:

\begin{abstract}
Através deste termo tento demarcar, em primeiro lugar, um conjunto decididamente heterogêneo que engloba discursos, instituições, organizações arquitetônicas, decisões regulamentares, leis, medidas administrativas, enunciados científicos, proposições filosóficas, morais, filantrópicas. Em suma, o dito e o não dito são os elementos do dispositivo. O dispositivo é a rede que se pode estabelecer entre estes elementos (FOUCAULT, 1979, p. 173).
\end{abstract}

Sabendo que os dispositivos são diversos, que se alojam nos recintos discursivos e legislativos da sociedade, e que desde uma simples confissão com o abade, até o falar sobre o sexo ou escondê-lo nas conversas corriqueiras, esses dispositivos da sexualidade sempre existiram e foram inseridos nos patamares de controle, pelo menos desde o século XVII em diante. Surgiu nesse sentido a ciência sexual que tipificava através da medicina eugenista o sujeito homossexual. Havia a discurso de "um terceiro sexo" que poderia ser controlado pelos dispositivos, que foram mais detidamente estudados por Foucault através da ciência do século XIX.

A vigilância e o poder profetizavam uma sociedade mantida sob o signo de uma ordem e os direitos ao ser humano estavam igualmente circunscritos a tal poder, no qual: 
O direito à vida, ao corpo, à saúde, à felicidade, à satisfação das necessidades, o 'direito' acima de tudo, acima de todas as opressões ou 'alienações', de encontrar o que se é e tudo o que se pode ser, esse 'direito' tão incompreensível para o sistema jurídico clássico, foi a réplica política a todos esses novos procedimentos de poder (FOUCAULT, 1988, p 133).

O poder/sexo surge como disciplinamento e pertencente a sociedade da biologia, da literatura, dos costumes, das casas de prostituição, dentre outros. Docilizar o sexo seria a palavra de ordem para os vitorianos. Havia medo, espanto, mas desejo de se pensar/fazer sexo.

Neste período do século XIX, a psiquiatria transitava como legisladora das perversões. E a homossexualidade era uma delas. E“a sexualidade, quanto a ela, encontra-se do lado da norma, do saber, da vida, do sentido, das disciplinas e das regulamentações". (FOUCAULT, 1988, p.139).

O sexo homoerótico ganhou definição pelo viés dos dispositivos da sexualidade. Pois:

o dispositivo da sexualidade suscitou um de seus princípios internos de funcionamento mais essenciais: o desejo do sexo desejo de tê-lo, de aceder a ele, de descobri-lo, liberá-lo, articulá-lo em discurso, formulá-lo em verdade. Ele constitui o sexo como desejável. (FOUCAULT, 1988, p.146)

A Resolução 001/99 sendo um atestado de conduta profissional do psicólogo apresenta-se como um veículo de entendimento desses dispositivos da sexualidade, ou indo um pouco mais, é uma forma jurídica de firmar acordo entre o estado e os cidadãos a favor dos homoeróticos. A ideia é de se fazer compreender a sexualidade homoerótica, respeitando-a em seu desejo. Estamos pela via do desejo e como disse Foucault "ele constitui o sexo como desejável". Quem? O discurso sobre o sexo através dos dispositivos sexuais.

Onde a sexualidade homoerótica era minada, o decreto 001/99 estabelece regras para se suprimir um controle heteronormativo vigente e preconceituoso. A ideia de perversão e patologia já não está em curso na atualidade com relação ao desejo homossexual, graças aos códigos jurídicos e ao distanciamento de uma norma que permanecia entranhada com as etiologias das parafilias de Krafft-Ebing e de seus esboços sobre a psicopatologia sexual (Cf. SPENCER, 1997) 
De acordo com o citado artigo $3^{\circ}$, a lembrar: "Os psicólogos não exercerão qualquer ação que favoreça a patologização de comportamentos ou práticas homoeróticas, nem adotarão ação coercitiva tendente a orientar homossexuais para tratamentos não solicitados" (Ibidem, 1999, p 2). Nesse fragmento está-se falando de práticas homoeróticas que para Foucault nas sociedades eugenistas eram discriminadas. E na psicologia contemporânea o ser homoerótico possui um desejo por eleição, elege-se um objeto de desejo e o ama. O psicólogo deve estar atento a essa perspectiva e não reproduzir um dispositivo sexual de coerção do desejo, como cita o artigo $3^{\circ}$.

Dadas às ordens da Resolução 001/99, devemos olhar para o que de fato ele representou na construção do sujeito, onde o lugar do decreto, na perspectiva atualizada, é de "fomentar novas formas de subjetividade mediante a recusa do tipo de individualidade que se impuseram a nós durante vários séculos" (FOUCAULT, 1988, p. 308).

E esta subjetividade é fator marcante nas linhas gerais da Resolução 001/99, pois a ideia é de demonstrar que os sujeitos gays têm uma história, tanto mundial, quanto no Brasil, de lutas e resistências às suas lutas. Pois, "se, para Michel Foucault praticar a homossexualidade é estar em devenir, a vivência homossexual não parece se contrapor ao estado de vir-a-ser de uma nação de grande enigmas e de identidade tão fluida quanto no Brasil”' (TREVISAN, 2000, p. 59).

A luta pela diversidade continua no CFP, entendendo que os homossexuais devem e podem transitar com liberdade e expressando livremente sua formação sexual, e que a sociedade eugenista de séculos anteriores não se revisitem ou se criem novas raízes nesse nosso século XXI. Se acaso criar, teremos respaldo na lei contra a discriminação dos homoeróticos.

Cabe aos psicólogos refletir a resolução, mas que sabemos que o mesmo deve estar consciente sobre esta questão e se utilizar de seu Código de Ética Profissional para ratificar a Resolução 001/99, contrapondo-se a intolerância sexual e de quaisquer gêneros, na manutenção de um atendimento profissional coerente e despido de anacronismos, partilhando "as formas e os campos possíveis do conhecimento" (FOUCAULT, 2009, p. 30), para as implicações do "poder-saber e de suas transformações históricas" (Ibidem, 2009, p. $30)$. 


\section{Considerações finais}

Pensar o sujeito homossexual sobre a vertente da patologia ou da doença, já não é mais possível na atualidade. Graças a Resolução 001/99 podemos aferir que esses sujeitos de desejo não são doentes ou perversos.

Desde a retirada da patologização dos códigos internacionais de doença, e também pela Organização Mundial da Saúde, o homossexual/gay/homoerótico ganhou o que era de direito: respeito à sua diversidade sexual, a Psicologia comemora a mais de uma década seu decreto que vai de encontro a quaisquer formas de homofobia.

Desde os dispositivos sexuais estudados por Foucault, a história do desejo homossexual tratou de se adequar a medicina da época vitoriana. Puramente eugenista e anacrônica. Com a percepção desses dispositivos a sexualidade podia ser adestrada e, curiosamente, interpelada pelas sociedades do biopoder.

O desejo, em sua terminologia (olhar para a sidera, a constelação), bem como o desejo de outrem em amar ao seu igual formaram uma relação equânime. A saber: o desejo é falta, mas vive em busca de seu par, de seu semelhante para se fazer completo. Entretanto, a Psicologia alude que a incompletude é característica do homem, e que com o entendimento desse desejo e, principalmente, com o entendimento do desejo homossexual, pode-se fazer uma incursão ao mundo do paciente/cliente/analisando, mas sem a sombra de curá-los e sim de fazê-los reencontrar a sua identidade sexual e amor-próprio.

O que se buscou nesse artigo foi de esclarecer através do processo legislativo do CFP, o que se pensa sobre as homossexualidades na atualidade, e como o profissional "psi" deve atuar frente às demandas de seus pacientes gays. É um ordenamento jurídico que observa a não patologização e eleva-nos criticamente para a erradicação total de comportamentos e ideias homofóbicas, remanescentes de uma sociedade eugenista e que nega o outro, o diverso, o estranho, pois o considera ameaçador a si. 
Precisamos melhorar, sabemos disso, nas questões sobre a sexualidade como um todo, mas que um passo já foi dado, e este passo veio pela Resolução 001/99 para os profissionais da ciência psicológica.

\section{Referências}

BOCK. A. M. B etalii. Psicologias: uma introdução ao estudo da psicologia. São Paulo: Saraiva, 2001.

CHAUÍ, M. Laços do desejo. In.: NOVAIS, a. (org). O desejo. Rio de Janeiro, Funarte, 1990.

CONSELHO FEDERAL DE PSICOLOGIA. Código de Ética Profissional do Psicólogo. Brasília, CFP, 2005.

CONSELHO FEDERAL DE PSICOLOGIA. Decreto $\mathbf{N}^{\mathbf{0}}$ 001/99. Brasília: CFP, 1999.

FOUCAULT, M. Microfísica do Poder. Organização e tradução de Roberto Machado. Rio de Janeiro: Graal, 1979.

FOUCAUlT, M. Vigiar e Punir: nascimento da prisão. 37. Ed. Petrópolis, Rio de Janeiro: Vozes, 2009.

FOUCAULT, M. História da sexualidade: a vontade de saber. Rio de Janeiro, Editora Graal. 1988.

FREUD, S. Estudos sobre a histeria [1893]. Rio de Janeiro: Imago, 1996 (Edição Brasileira das obras completas de Sigmund Freud, volume 2).

FRY, P.: Caminhos cruzados: linguagem, antropologia e ciências naturais. São Paulo: Brasiliense, 1982.

GOMES, Y. Psicologia e diversidade sexual. Conselho Regional de psicologia $15^{\mathrm{a}}$ região. Alagoas: 2010. Disponível em <<http://www.subsites.crp15.org.br/conteudo_det.php?nid=470>> Acesso em Maio de 2014. 
KAHHALE, E. M. P. Histórico do sistema conselhos de psicologia: as interfaces com as questões LGBTs. In.: Conselho regional de psicologia da $6^{\text {a }}$ região (Org). Psicologia e diversidade sexual. São Paulo: CRPSP, 2011.

LACAN, J. Função e campo da fala e da Linguagem. In: Escritos. Rio De Janeiro: Jorge Zahar Ed., 1998.

LAPLANCHE, J; PONTALIS. Vocabulário da Psicanálise. São Paulo: Martins Fontes, 1970.

LIVRO DO GÊNESIS. In.:Bíblia Sagrada. Tradução Ecumênica. São Paulo: Edições Loyola, 1994.

MIJOLLA, A. Dicionário internacional da psicanálise. Rio de Janeiro: Imago 2005.

PLATÃO. Banquete. Trad. José Cavalcante de Souza. São Paulo: Editora Nova Cultural. Ed. 5. 1991.

RAUPP, R. Para um direito democrático da sexualidade. Horizontes Antropológicos. Porto Alegre, ano 12, n. 26, p. 71-100, jul.-dez. 2006.

SPENCER, C. Homossexualidade: uma história. Rio de Janeiro: Record, 1997.

TREVISAN, J. S. Devassos no paraíso: a homossexualidade no Brasil. Da colônia à atualidade. Rio de Janeiro: Record, 2000.

UZIEL, A. P. Famílias LGBTs. In.: Conselho regional de psicologia da $6^{\text {a }}$ região $(\mathrm{Org})$. Psicologia e diversidade sexual. São Paulo: CRPSP, 2011.

VEIGA-NETO, A. Foucault e a educação. 2.ed. Belo Horizonte: Autêntica, 2007.

WILDER, O. De profundis e outros escritos do cárcere. Porto Alegre: L\&PM, 1998. 